\title{
Punahomealttius ohra- ja kauralajikkeissa
}

\author{
Päivi Parikka ${ }^{1}$, Arjo Kangas ${ }^{2}$ Merja Högnäsbacka ${ }^{2}$ ja Anja Weckman ${ }^{2}$ \\ MTT Kasvintuotannon tutkimus, \\ ${ }^{1}$ Kasvinsuojelu, 31600 Jokioinen \\ ${ }^{2}$ Peltokasvitutkimus, 61400 Ylistaro
}

Mykotoksiinit muodostavat turvallisuusriskin viljaa ravintona käyttäville ihmisille ja viljarehua syöville eläimille. Toksiineista johtuvat syömis- ja lisääntymishäiriöt voivat johtaa huomattaviin taloudellisiin menetyksiin kotieläintuotannossa. Viileän ilmaston maissa Fusarium-suvun sienet ovat yleisimpiä toksiinien muodostajia viljassa. Kasvukauden kuluessa saatu tartunta jyvissä voi johtaa sopivissa oloissa toksiinien muodostumiseen. Viljalajeista kauraa pi-detään alttiina Fusarium-tartunnalle ja sillä tavataan usein korkeita toksiinipitoisuuksia. Ohra on kuitenkin yhtä yhtä arka tartunnalle ja sillä tavataan myös runsaasti toksiineja.

Punahomeita aiheuttavien Fusarium-sienten tartuntaa määritettiin MTT Ylistaron toimipaikan virallisissa lajikekokeissa 2008-2009 vertailtavina olevista kaura- ja ohralajikkeista. Ohrasta tutkittiin kumpanakin vuonna 31 lajiketta. Kauran lajikkeita ja jalostuslinjoja tutkittiin 200824 ja 200920. Tähkä- ja röyhynäytteitä otettiin koealueilta, joita ei käsitelty fungisideilla. Fusarium-tartunnan kehitystä seurattiin tähkälle tulosta aina valmiiseen satoon asti.

Kahden kesän olosuhteet olivat erilaisia sade- ja lämpöoloiltaan. Kesä 2008 oli viileä ja sateinen, 2009 kuivempi ja lämpimämpi. Ohrista monitahoiset lajikkeet olivat 2008 alttiimpia Fusariumtartunnalle kuin kaksitahoiset. Kesän 2009 havainnoissa Fusarium-tartunta runsastui nopeammin kuin edellisenä vuonna. T2/HT-2-toksiinien muodostajista F. langsethiae- laji tartutti silloin kauran lisäksi ohraa verrattain runsaasti jo heinäkuun jälkipuoliskolla. Myös deoksinivalenolin (DON)-muodostajien määrä lisääntyi jo ennen elokuuta eräillä lajikkeilla.

Lajikkeiden välillä oli suuria eroja Fusarium-tartunnassa. Aikaiset lajikkeet säästyvät usein hometartunnoilta myöhäisiä paremmin, mutta kaikki lajikkeiden väliset erot eivät selity niiden valmistumisella. Kauralla DON-muodostajia havaittiin ennen sadonkorjuuta eniten 'Aslak'-, 'Fiia'-, 'Ivory' 'Julius''Steinar'-, ja 'Roope'-lajikkeilla. Ohrista eniten tartuntaa todettiin 'Olavi'-, 'Vilde'-, 'Einar'-, 'Edel'-, 'Conchita'-, 'Ingmar'-, 'Afrodite'-, 'Kunnari'- ja 'Malta-sia'-lajikkeilla.

T2/HT-2 -toksiinien muodostajia oli valmistuvassa sadossa 2008 vähemmän kuin 2009. Kauralajikkeista 'Eemeli', 'Roope', 'Aarre’, 'Carron' ja 'Ivory’ saivat kohtalaisesti tartuntaa. Ohralla lajeja esiintyi 2008 vähän. Kuitenkin 2009 ohralajikkeilla F. langsethiae oli jopa yleisempi kuin kauroilla. Erityisesti 'Umbrella', 'Maltasia' ja 'Olavi’ olivat saastuneita.

Tutkimus täydentää lajikekokeista tehtäviä kasvitautihavaintoja, mutta ei pysty tuottamaan tietoa kaikista lajikkeista. Fusarium-alttius ennakoi sadon hävikkiä surkastuneina jyvinä ja laatua elintarvikkeeksi, rehuksi ja mallastukseen. Fusarium-alttiuden tunteminen auttaa arvioimaan myös tuotetun sadon toksiiniriskiä. 


\section{Johdanto}

Mykotoksiinit muodostavat turvallisuusriskin viljaa ravintona käyttäville ihmisille ja viljarehua syöville eläimille. Homesienten muodostamat toksiinit ovat myrkyllisiä jo pieninä pitoisuuksina ja niiden jatkuva saanti voi aiheuttaa kroonisia terveyshaittoja. Akuutit myrkytykset ovat meillä harvinaisempia kuin lämpimän ilmaston maissa, joissa säilytys- ja kasvuolot altistavat viljaa toksiinien muodostumiselle. Kuitenkin eläimille aiheutuvat, toksiineista johtuvat syömis- ja lisääntymishäiriöt voivat aiheuttaa huomattavia taloudellisia menetyksiä. Viileän ilmaston maissa Fusarium-suvun sienet ovat yleisimpiä toksiinien muodostajia viljassa, lämminilmakuivatusta käytettäessä Penicillium- ja Aspergillus-sienten muodostamia okratoksiineja esiintyy harvemmin.

Kasvukaudella tapahtuvat punahometartunnat heikentävät sadon laatua ja lisäävät hometoksiiniriskiä. Toksigeenisten homeiden lajikirjon ja riskien on ennustettu lisääntyvän ilmaston lämpenemisen myötä myös pohjoisilla viljelyalueilla. Erityisesti kauralla riski sadon laadun heikkenemiseen on selkeästi todettu sekä vuotuisessa viljan hometoksiiniseurannassa (www.cerveg.fi) että viime vuosina tehdyissä tutkimuksissa. Hometoksiinien muodostumisen lisäksi Fusarium-tartunta heikentää jyvien kehitystä ja vaikuttaa siten sadon laatuun ja määrään.

Viljalajien välillä on eroja alttiudessa Fusarium-saastunnalle (Liu \& al, 1997). Kauraa on pidetty altteimpana Fusarium-sienille, mutta norjalaisten tutkimusten mukaan ohralla tartuntaa esiintyy yhtä usein (Langseth \& Elen, 1996). Meillä tiedot toksiinien esiintymisestä ja viljan Fusarium-lajistosta viittaavat samaan mahdollisuuteen. Viljalajien väliset erot johtuvatkin usein tutkitun viljan erilaisesta alkuperästä, sillä ympäristöolot vaikuttavat selvästi toksiinimuodostukseen.

Fusarium-lajeja on selvitetty suomalaisesta viljasta useaan otteeseen 1970-luvulta lähtien, jolloin esiintyi runsaasti niiden muodostamia mykotoksiineja (Ylimäki \& al, 1979). Meillä ja muissa Pohjoismaissa vallitsevana lajina on $F$. avenaceum, joka ei ole yleisemmin esiintyvän deoksinivalenolin (DON) tuottaja, mutta tuottaa meillä vähemmän huomioitua moniliforminia (Uhlig \& al, 2007). Lajia esiintyy erityisen runsaana sateisina ja viileinä kesinä, kuten 1998 (Eskola \& al, 2001, Henriksen 1999). Tähkävioituksia aiheuttava Fusarium-lajisto vaihtelee Euroopan eri alueilla johtuen lajien erilaisita olosuhdevaatimuksista. Tärkeimmät lajit ovat Fusarium graminearum, F. culmorum ja $F$. avenaceum. Vähemmän tärkeinä pidettyjä lajeja, mutta myös hometoksiinien tuottajia ovat $F$. poae, F. tricinctum ja F. sporotrichioides. F. graminearum on tärkein deoksinivalenolin (DON) tuottaja Euroopan lämpimillä alueilla, kun taas $F$. culmorum on merkittävin toksiinintuottaja viileämmillä alueilla. Pohjoisessa F. poae on tärkeä nivalenolin (NIV) tuottaja ja F. sporotrichioides muodostaa T2/HT-2 toksiineja (Bottalico \& Perrone, 2002). Norjassa on viime vuosina todettu tärkeimmäksi T2/HT-2-toksiinien tuottajaksi $F$. langsethiae (Kosiak \& al, 2003). Nämä toksiinit ovat nousemassa uudeksi viljan laatuongelmaksi Euroopassa (Edwards \& al, 2009). Lämmin ja kostea sää tähkälletulon ja kukinnan aikaan suosii Fusarium- tartuntaa ohralla ja vehnällä (Xu, 2003), mutta kauran tartunnasta tiedetään hyvin vähän (Langseth \& Elen, 1996). T2/HT-2 muodostajat $F$. langsethiae ja $F$. sporotrichioides viihtyvät kuivassa ja lämpimässä samoin nivalenolia muodostava $F$. poae (Thrane \& al, 2004).

Kaura- ja ohralajikkeiden välillä on havaittu eroja sekä Fusarium-tartunnassa että toksiinipitoisuuksissa (Parikka \& al, 2005), mutta tutkimustietoa lajikkeiden eroista on toistaiseksi vähän.

\section{Aineisto ja menetelmät}

\section{Näytteenotto}

MTT Ylistaron toimipaikan virallisista lajikekokeista valittiin 2008-2009 näytteenottoon kaura- ja ohralajikkeita niiden nykyisen yleisyyden ja oletettavissa olevan tulevan käytön mukaan. Ohrasta tutkittiin kumpanakin vuonna 31 lajiketta. Kauran lajikkeita ja jalostuslinjoja tutkittiin 200824 ja 200920. Tähkä- ja röyhynäytteitä otettiin koealueilta, joita ei käsitelty fungisideilla. Näytteenotto aloitettiin viljan tullessa tähkälle/röyhylle ja sitä jatkettiin joka toinen viikko sadonkorjuuseen asti. Lisäksi tutkittiin valmista, puitua satoa.

\section{Fusarium-sienten eristys näytteistä}

Punahomeiden esiintyminen kehittyvissä jyvissä tutkittiin maljaamalla tähkylät pentakloronitrobentseeniä (PCNB) sisältävälle alustalle (Nelson \& al, 1983). Rihmastot siirrostettiin tunnistusta varten pe- 
runadekstroosialustalle (PDA). Fusarium-lajit tunnistettiin viljelmistä silmävaraisesti ja mikroskoopilla.

\section{Tulokset ja tulosten tarkastelu}

Kasvukausien sääolot olivat Etelä-Pohjanmaalla erilaiset. Kesä 2008 oli Etelä-Pohjanmaalla viileä ja sateinen. Vuoden 2009 kasvukausi oli lämmin ja osin kuiva. Se vaikutti viljan punahometartuntaan ja hometoksiinien muodostumiseen. F. avenaceum hyötyi viileydestä ja kosteudesta, mikä näkyi erityisesti kauralla, mutta myös joillakin ohralajikkeilla (Kuvat 1. ja 2.) Yleisimmän toksiinin, deoksinivalenolin (DON) muodostajat Fusarium culmorum ja F. graminearum viihtyvät parhaiten lämpimässä (Xu, 2003). Ne tarvitsevat tartuntaan kosteutta, mutta toksiineja muodostuu parhaiten vaihtelevissa, vuoroin kuivissa ja kosteissa oloissa. Kosteutta oli tartunnalle riittävästi 2008, mutta lajit runsastuivat viileyden takia melko myöhään, mikä vaikutti toksiininmuodostukseen. Kesän 2009 kuivuus ehkäisi $F$. culmorum ja F. graminearum-tartuntaa, joka jäi osin vähäiseksi. T2/HT-2 toksiinien muodostajia, $F$. langsethiae ja $F$. sporotrichioides esiintyi viljassa 2008, mutta määrät eivät olleet kovin korkeita. $F$. langsethiae on lajeista runsaampi kauralla, mutta sitä esiintyy myös joillakin ohralajikkeilla suhteellisen runsaasti. Muiden Fusarium-lajien, erityisesti F.avenaceum-lajin runsaus heikensi T2/HT-2 toksiinien muodostajien kasvua ja saattoi myös vaikuttaa toksiininmuodostukseen. Kesän 2009 oloissa F. langsethiae viihtyi hyvin, sillä lämmin ja kuiva sää suosii sitä ja $F$. sporotrichioides-lajia (Thrane \& al, 2004).

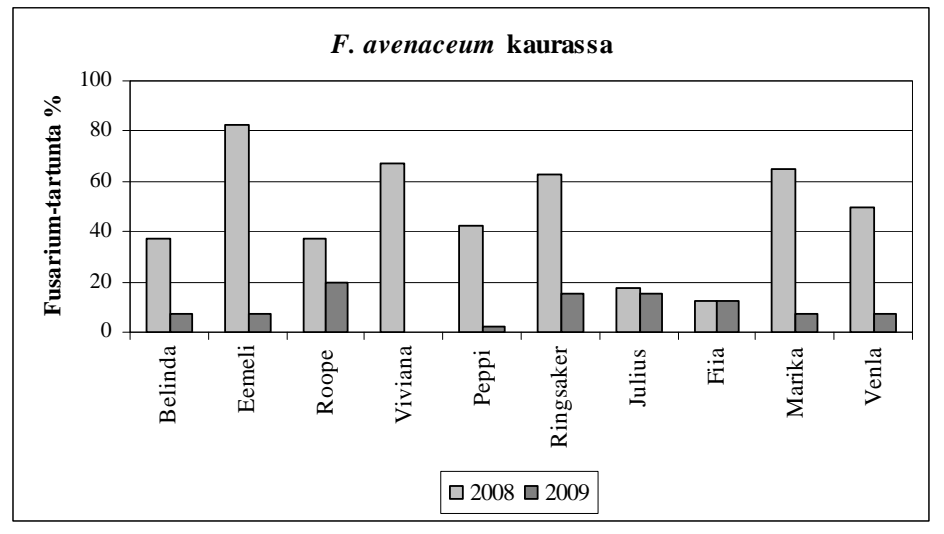

Kuva 1. F. avenaceum-tartunnan runsaus kauralajikkeilla 2008 ja 2009 ennen sadonkorjuuta otetuissa näytteissä.

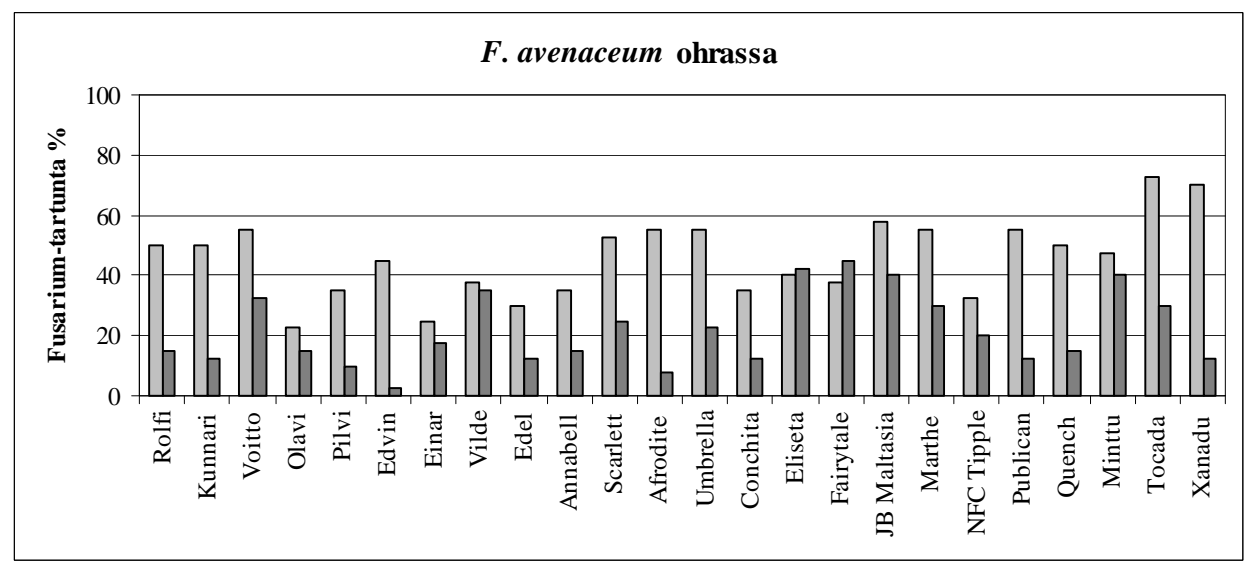

Kuva 2. F. avenaceum-lajin runsaus ohralajikkeilla ennen sadonkorjuuta 
Fusarium-tartunta kehittyi 2008 kosteassa nopeammin kuin 2009. Poikkeuksena F. langsethiae, joka yleistyi 2009 ohralla aikaisemmin kuin kauralla. Elokuussa tuleentumattomasta viljasta kerätyissä tähkylänäytteissä laji oli 2008 yleisempi kauralla kuin ohralla, mutta 2009 tilanne oli päinvastainen (Kuvat 3. ja 4.). Erityisesti tartuntaa havaittiin kaksitahoisilla lajikkeilla.

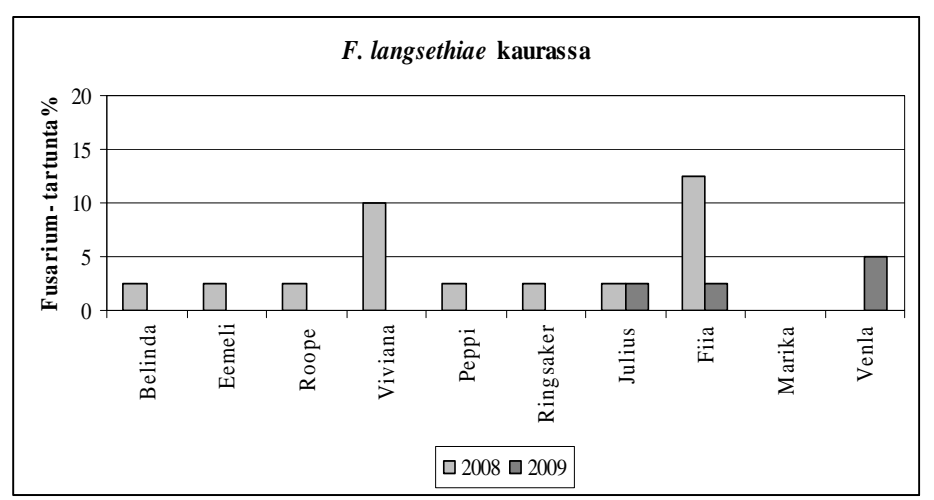

Kuva 3 . T-2/HT-2 tuottaja F. langsethiae kauralajikkeissa elokuussa (2008 11.8. ja 2009 14.8.) tuleentumattomasta viljasta kerätyissä näytteissä

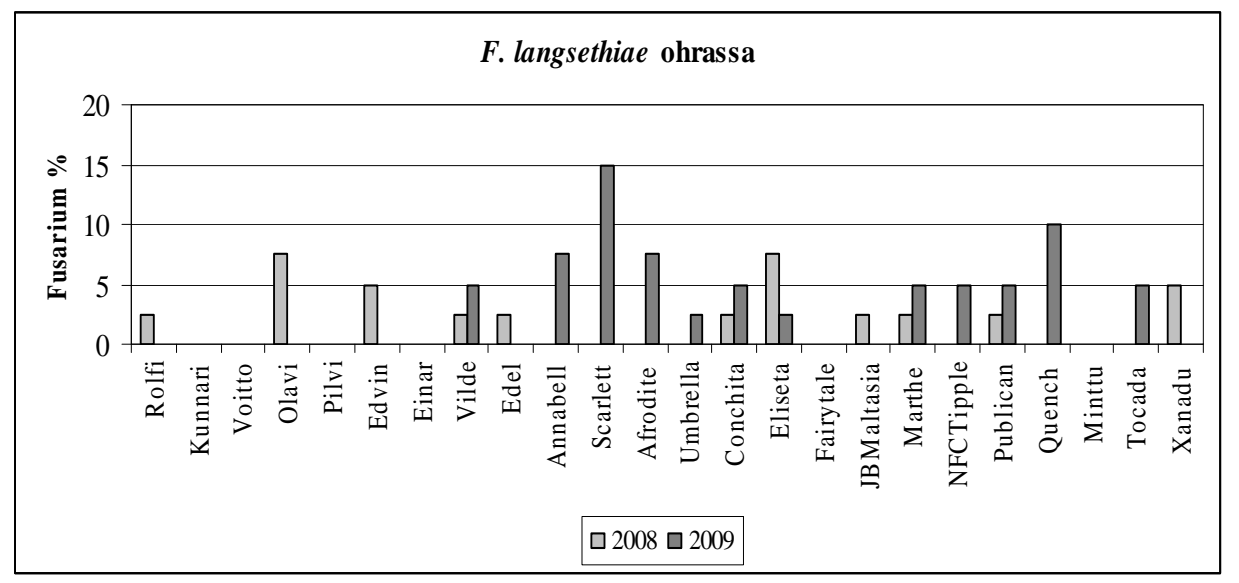

Kuva 4. T-2/HT-2 tuottaja F. langsethiae ohralajikkeissa elokuussa (6.8.) tuleentumattomasta viljasta kerätyissä näytteissä

Kauralajikkeista deoksinivalenolin tuottajia oli eniten 'Fiia'-, 'Julius'- ja 'Aslak'-lajikkeissa. Näistä 'Julius'-lajikkeessa voimakkaampi toksiinintuottaja $F$. graminearum oli runsaampi, toisin kuin muissa lajikkeissa, joissa F. culmorum oli vallitseva laji (Kuva 5.). Toisaalta 2008 'Carron'-lajikkeessa DONtuottajia oli hyvin niukasti. T2/HT-2 tuottajia oli runsaimmin 'Eemeli'-, 'Aarre'-, 'Ivory'- ja 'Carron'lajikkeissa. 'Fiia' - ja 'Roope’-lajikkeissa F. langsethiae-tartunta alkoi 2008 muita aikaisemmin ja 'Venlassa' tartuntaa oli hyvin vähän 


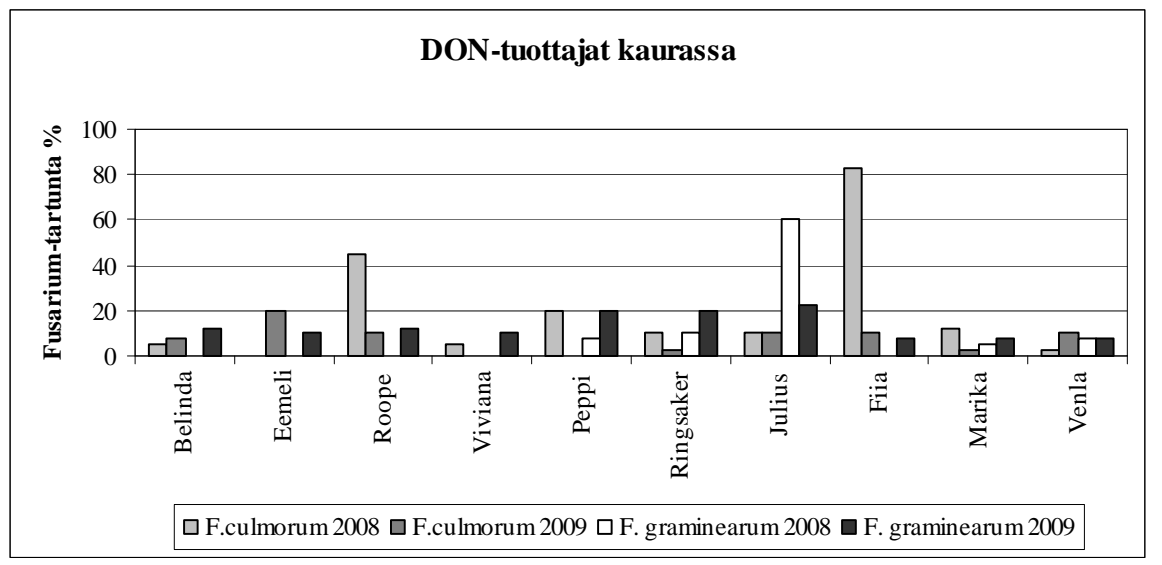

Kuva 5. Deoksinivalenolin (DON) tuottajien runsaus kauralajikkeilla ennen sadonkorjuuta.

Monitahoisista ohrista deoksinivalenolin tuottajia oli runsaasti useissa lajikkeissa. 'Edel', 'Vilde', 'Rolfi', 'Einar', 'Pilvi' ja 'Olavi' olivat lajikkeita, joissa F. culmorum-tartunta oli runsain. T2/HT-2 toksiinien tuottajia oli runsaimmin 'Voitto-lajikkeessa, myös 'Vilde'-, 'Olavi'- ja 'Pilvi'-lajikkeissa tartuntaa oli melko runsaasti (Kuva 6.). 2-tahoisista lajikkeista 'Conchita'-, 'Maltasia'- ja 'Ingmar'lajikkeissa oli runsas F. culmorum-tartunta. F. graminearum oli runsain 2009 'Afrodite'-lajikkeella. 'Minttu'- ja 'Ingmar'-lajikkeissa puolestaan F. graminearum oli muita runsaampi T2/HT-2 tuottajia oli 2-tahoisissa lajikkeissa vuonna 2008 vähän, vain 'Tocada'-lajikkeessa oli merkittävämmin $F$. langsethiae-tartuntaa. Vuoden 2009 säät suosivat lajia, jota havaittiin ohralla kehittyvissä jyvissä jopa enemmän kuin kauralla

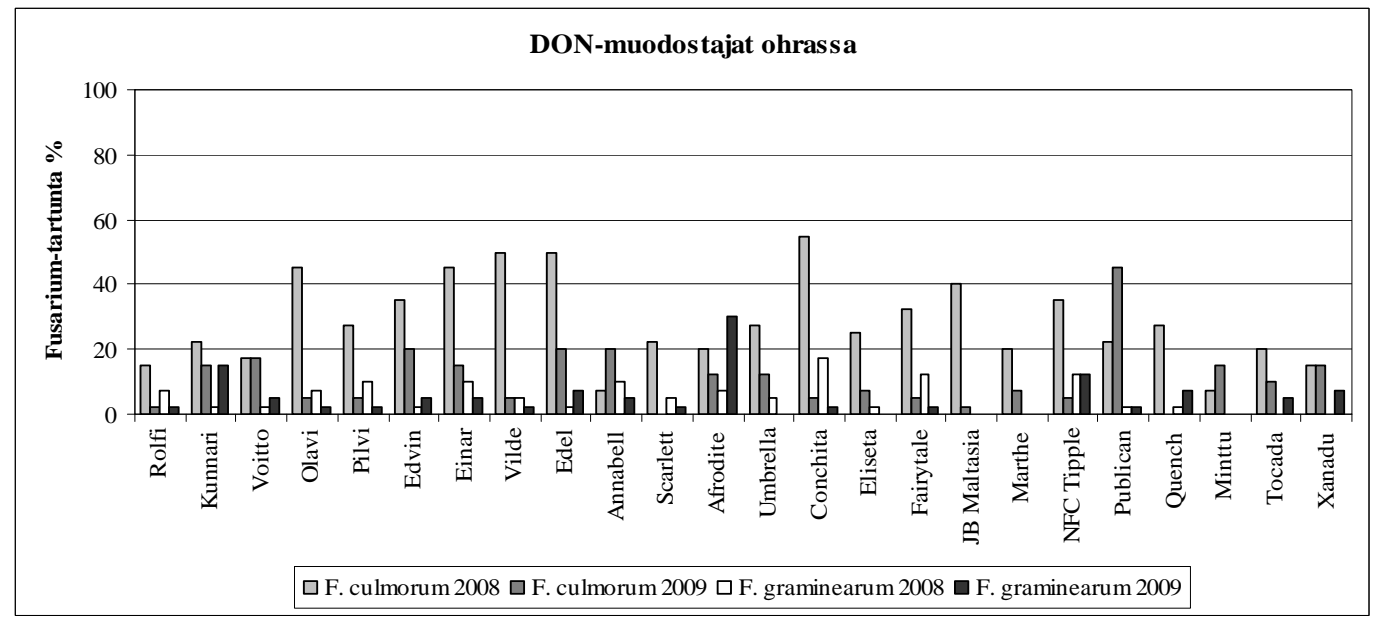

Kuva 6. Deoksinivalenolin (DON) tuottajien runsaus ohralajikkeilla ennen korjuuta.

\section{Johtopäätökset}

Havaitut toksiinintuottajien määrät olivat merkittäviä ja lämpimänä kesänä korkeidenkin toksiinipitoisuuksien riski on olemassa eräillä Fusarium-lajeille alttiilla lajikkeella. Lajikkeiden välillä oli suuria eroja ja mukana oli myös lajikkeita, joissa Fusarium-tartunta oli hyvin vähäistä. Lajikealttiuden tunteminen luo mahdollisuuden tuottaa turvallista satoa elintarvike- ja rehukäyttöön. Valitsemalla kestävimpiä lajikkeita turvataan sadon mahdollisimman hyvä kelpoisuus myös asetettujen toksiinien enimmäismäärien puitteissa. Mallastukseen käytettävillä ohralajikkeilla homeet vaikuttavat sadon käyttökelpoisuuteen. 


\section{Kirjallisuus}

Bottalico, A. \& Perrone, G. 2002. Toxigenic Fusarium species and mycotoxins associated with head blight in small-grain cereals in Europe. European Journal of Plant Pathology 108:611-624.

Edwards, S.G., Barrier-Guillot, B., Clasen, P.E., Hietaniemi, V. Pettersson, H. 2009. Emerging issues of HT-2 and T-2 toxins in European cereal production. World Mycotoxin Journal 2: 173-179.

Eskola, M., Parikka, P. \& Rizzo, A. 2001. Trichothecenes, ochratoxin A and zearalenone contamination and Fusarium infection in Finnish cereal samples in 1998. Food samples in 1998. Food additives and contaminants 18, 8/2001: 707-718.

Henriksen, B. 1999. Factors affecting Fusarium infection and mycotoxin contents in cereal grains. Dissertation 98 pp. Agricultural University of Norway.

Jennings, P. \& Turner, J.A. 2000. Overview of Fusarium ear blight in the UK- effect of fungicide treatment on disease control and mycotoxin production. BCPC Conference- Pests \& Diseases 2000: 707-712.

Kosiak, B. Torp, M, Skjerve, E.\& Thrane, U. 2003. The prevalence and distribution of Fusarium species in Norwegian cereals: a survey. Acta Agriculturae Scandinavica, Section B, Soil and Plant Science 53:168-176.

Langseth, W. \& Elen, O. 1996. Differences Between Barley, Oats and Wheat in the Occurence of Deoxynivalenol and other Trichothecenes in Norwegian Grain. J. Phytopathology 144:113-118.

Liu, W., Langseth, W., Skinnes, H., Elen, O. \& Sundheim, L. 1997. Comparison of visual blight ratings, seed infection levels and deoxynivalenol production for assessment of resistance in cereals inoculated with Fusarium culmorum. European J. Plant Pathology 103: 589-595.

Nelson, P. E., Toussoun, T. A. \& Marasas, W. F. O. 1983. Fusarium Species: An Illustrated Manual for Identification. Pennsylvania State University Press, University Park.

Parikka, P., Hietaniemi, V. \& Rämö, S. 2005. The effect of tillage on Fusarium infection and mycotoxins on barley and oats. In: The BCPC international congress Crop science \& technology 2005 : congress proceedings, volume 1, SECC, Glasgow, Scotland, UK, 31 Oct - 2 Nov 2005. Glasgow: BCPC. p. 423-428.

Thrane, U., Adler, A., Clasen, P.-E., Galvano, F., Langseth, W., Lew, H., Logrieco, A., Nielsen, K. \& F. Ritieni, A. 2004. Diversity in metabolite production by Fusarium langsethiae, Fusarium poae and Fusarium sporotrichioides. International Journal of Food Microbiology 95:257-266.

Uhlig, S., Jestoi, M. \& Parikka, P. 2007. Fusarium avenaceum- The North European situation. International Journal of Food Microbiology: 17-24.

Xu, X. 2003. Effects of environmental conditions on the development of Fusarium ear blight. European Journal of Plant Pathology 109:683-689.

Ylimäki, A., Koponen, H., Hintikka E.L., Nummi, M., Niku-Paavola, M-L.,Ilus, T.\& Enari, T.-M. 1979. Mycoflora and occurence of Fusarium toxins in Finnish grain. Technical research centre of Finland, Materials and Processing Technology Publication. 1979. 21, 28pp. 